\title{
Big Five Traits as Predictors of Perceived Stressfulness of the COVID-19 Pandemic
}

\author{
Hannes Zacher ${ }^{1}$ and Cort W. Rudolph ${ }^{2}$ \\ ${ }^{1}$ Institute of Psychology - Wilhelm Wundt, Leipzig University \\ ${ }^{2}$ Department of Psychology, Saint Louis University
}

Please cite as:

Zacher, H. \& Rudolph, C. W. (2021, in press). Big Five traits as predictors of perceived stressfulness of the COVID-19 pandemic. Personality and Individual Differences.

\section{Author Note}

Hannes Zacher (D) https://orcid.org/0000-0001-6336-2947

Cort W. Rudolph (iD https://orcid.org/0000-0002-0536-9638

The study reported in this article is funded by Volkswagen Foundation.

Correspondence concerning this article should be addressed to Hannes Zacher, Institute of Psychology - Wilhelm Wundt, Leipzig University, Neumarkt 9-19, 04109 Leipzig, Germany. Email: hannes.zacher@uni-leipzig.de 


\begin{abstract}
This study examined the Big Five personality traits as predictors of individual differences and changes in the perceived stressfulness of the COVID-19 pandemic in Germany between early April 2020 and early September 2020. This timeframe includes the first national "lockdown," the period of "easing" of restrictions, and the summer vacation period. Data were collected from $n=$ 588 full-time employees, who provided baseline data on their personality traits in early December 2019, and then later provided data on perceived stressfulness of the COVID-19 pandemic at five time points, spanning six months. Consistent with expectations based on event and transition theories, results showed that, on average, perceived stressfulness declined between early April 2020 and early September 2020. Moreover, this effect was stronger between early April 2020 and early July 2020. Hypotheses based on the differential reactivity model of personality and stress were partially supported. Emotional stability was associated with lower, and extraversion associated with higher, average levels of perceived stressfulness. Finally, extraversion was associated with increases (i.e., positive trajectories) in perceived stressfulness between early April 2020 and early July 2020 and decreases (i.e., negative trajectories) in perceived stressfulness between early July 2020 and early September 2020.
\end{abstract} Keywords: COVID-19; stressfulness; Big Five; pandemic 


\section{Big Five Traits as Predictors of Perceived Stressfulness of the COVID-19 Pandemic}

Since the World Health Organization officially declared COVID-19 a pandemic on $11^{\text {th }}$ March 2020, it has significantly impacted people's lives around the globe. For instance, the crisis has led to major changes and uncertainty in the domains of work (Rudolph et al., 2020) and family (Prime et al., 2020). A number of longitudinal studies have already shown that national "lockdowns" during the early stages of the pandemic have reduced people's mental health and subjective wellbeing (e.g., Sibley et al., 2020; Zacher \& Rudolph, 2021). Additionally, several cross-sectional studies have shown that individuals' personality traits are associated with how they appraise and react to the pandemic in terms of mental health (e.g., depressive symptoms, generalized anxiety; Nikčević et al., 2020), subjective wellbeing (Modersitzki et al., 2020; Somma et al., 2020), and (mal-)adaptive coping responses (Bacon \& Corr, 2020; Volk et al., 2020). For example, a survey study conducted in Canada in early May 2020 found that higher extraversion and lower emotional stability were related to higher perceived stress during the COVID-19 pandemic (Liu et al., 2020).

However, currently there is a lack of knowledge on (a) how perceived stressfulness of the COVID-19 pandemic developed over time and (b) the role of personality traits as predictors of both individual differences and changes over time in people's appraisals of the COVID-19 pandemic and, in particular, its perceived stressfulness. This is problematic, because stress is a dynamic process during which psychological reactions to a novel, disruptive, and critical event (Morgeson et al., 2015), such as the COVID-19 pandemic and associated measures like "lockdowns," may increase, decrease, or remain stable over time (Bliese et al., 2017; Schlossberg, 1981). Moreover, these trajectories in perceived stressfulness may depend on people's personality traits (Bolger \& Zuckerman, 1995). Knowledge regarding the personality 
traits that predict average levels and changes in perceived stressfulness over time is important to design and implement targeted and timely interventions to support those who need most help during the crisis.

Accordingly, the goals of this longitudinal study are twofold. First, based on event and transition theories (Bliese et al., 2017; Morgeson et al., 2015; Schlossberg, 1981), we examine changes in perceived stressfulness of the COVID-19 pandemic in Germany between early April 2020 and early September 2020. This timeframe includes the first national "lockdown" period (late March 2020 to early May 2020), the period of "easing” of restrictions (early May 2020 to early July 2020), and the summer vacation period (early August 2020 to early September 2020). Perceived stressfulness is an indicator of low emotional wellbeing or high strain that arises due to appraisals of a situation as a (potentially) uncontrollable threat to one's personal goals and resources (Lazarus \& Folkman, 1984; Peacock \& Wong, 1990). Second, based on the differential reactivity model of personality and stress (Bolger \& Zuckerman, 1995; Vollrath, 2001), we investigate individual differences in the Big Five personality traits (i.e., extraversion, emotional stability, conscientiousness, agreeableness, openness to experience; Digman, 1990) as predictors of average levels and changes in perceived stressfulness of the COVID-19 pandemic. For our hypotheses, we focused on those two traits of the Big Five framework (or Five Factor Model) that are generally considered most relevant for people's emotional experience and wellbeing: extraversion and emotional stability (e.g., Costa \& McCrae, 1980; Hayes \& Joseph, 2003; Matthews \& Gilliland, 1999).

\section{Decline in Perceived Stressfulness of the COVID-19 Pandemic}

We first hypothesize that, on average, individuals' perceived stressfulness of the COVID19 pandemic declined between early April 2020 and early September 2020. During the first 
national "lockdown” in Germany between late March 2020 and early May 2020, public and business life as well as people's personal lives were severely restricted. During this period, children were not able to attend daycare or school, many workers had to work from home or involuntarily reduced their work hours, infected people and those who had contact with them had to quarantine, and many people felt socially isolated due to social distancing measures (e.g., no public events or private parties were allowed). The "lockdown" and other measures to deal with the COVID-19 pandemic in Germany were unprecedented in the country's modern history (i.e., since 1949). According to event system theory (Morgeson et al., 2015), the "lockdown" and the pandemic more generally can be considered strong events that were highly novel, disruptive, and critical and, therefore, likely had an impact on people's perceived stressfulness. Specifically, such events may thwart need satisfaction (e.g., needs for autonomy and relatedness; Ryan \& Deci, 2000) and consume and threaten valued personal resources (e.g., time, energy, health; Hobfoll, 2011).

Following the "lockdown," there was a period of progressively "easing" the restrictions in public and business life between early May 2020 and early July 2020, when daycares, schools, and businesses reopened, and people were again allowed to meet with members of other households. Based on transition theories (Bliese et al., 2017; Schlossberg, 1981), we expect that perceived stressfulness will show the steepest decline during this period of "easing" of restrictions immediately following the "lockdown." After this period, we expect a significantly weaker decline in perceived stressfulness of the COVID-19 pandemic between early July 2020 and early September 2020. During this later period, the six-week summer vacation took place and most restrictions regarding travel and social gatherings were lifted (n.b., the 16 German states differ in the start dates of vacation periods, tied to school schedules, as a means of 
reducing traffic congestion associated with travel to-and-from popular vacation destinations). Transition theories suggest that strong events can lead to enduring changes in people's experiences and behaviors (Bliese et al., 2017; Schlossberg, 1981). Adaptation to such transitions entails "a process during which an individual moves from being totally preoccupied with the transition to integrating the transition into his or her life" (Schlossberg, 1981, p. 7). Thus, transition theories propose that people increasingly adapt to strong events and, over time, perceive them as less stressful. This adaptation process is associated with stronger initial decreases in perceived stressfulness, as individuals quickly learn to cope with the stressful event. However, as time progresses, the event (e.g., a "lockdown") becomes less novel, disruptive, and critical and people have already adapted to it to some extent. This leads to weaker decreases in perceived stressfulness at later time periods, as compared to earlier periods, following the onset of the event. In summary, based on event and transition theories, as well as the progression of events associated with the COVID-19 pandemic in Germany, we expect an "L-shaped" trend in perceived stressfulness of the pandemic between early April 2020 and early September 2020.

Hypothesis 1: On average, there is a decline in the perceived stressfulness of the COVID19 pandemic between early April 2020 and early September 2020, with a steeper decline during the early stages of the pandemic (i.e., between early April 2020 and early July 2020) than during subsequent stages of the pandemic (i.e., between early July 2020 and early September 2020).

\section{The Role of Extraversion and Emotional Stability}

Event and transition theories postulate that individual differences, such as personality traits, can impact the direction and strength of adaptation processes (Bliese et al., 2017; Morgeson et al., 2015; Schlossberg, 1981). Accordingly, we hypothesize that higher extraversion is associated with higher average levels of perceived stressfulness of the COVID-19 pandemic 
across the study period. More extraverted people should appraise the various restrictions to public and social life associated with the pandemic, particularly social distancing and quarantine measures, as more threatening to their needs and personal goals than less extraverted people (Folk et al., 2020). For instance, more extraverted people enjoy social gatherings and interactions with other people, which were prohibited during the "lockdown" period of the pandemic. In contrast, the needs of less extraverted people are less likely frustrated during the COVID-19 pandemic, because they do not mind spending time on their own. Indeed, research has shown that particularly the sociability component of extraversion accounts for the association between this trait and wellbeing (Hotard et al., 1989). More recently, a study with over 93,000 participants from 47 countries found that the stringency of protective measures (e.g., travel restrictions, ban of public events) during the early stages of the COVID-19 pandemic (i.e., end of March to early April 2020) was associated with fewer depressive symptoms among less extraverted people, whereas there was no significant relationship among more extraverted people (Wijngaards et al., 2020). Another cross-sectional study found that extraversion was negatively related to health- and COVID-19-related anxiety and, in turn, depressive symptoms and generalized anxiety (Nikčević et al., 2020).

We further expect that higher emotional stability is associated with lower average levels of perceived stressfulness of the COVID-19 pandemic, because emotionally stable people are generally better able to cope with stressful situations and to regulate their emotions than less emotionally stable people (Hayes \& Joseph, 2003). Indeed, research shows that less emotionally stable people react more strongly to stressful events than more emotionally stable people (Bolger \& Schilling, 2006). Consistently, recent cross-sectional studies found that emotional stability was positively related to resilience (Kocjan et al., 2020) and negatively related to perceived threat, 
perceived stress, depressive symptoms, and anxiety during the COVID-19 pandemic (Lee \& Crunk, 2020; Liu et al., 2020; Nikčević et al., 2020; Pradhan et al., 2020). Moreover, a largescale experience sampling study with over 38,000 momentary reports provided by 1,609 participants found that less emotionally stable individuals paid more attention to information related to the COVID-19 pandemic, worried more about the consequences of the pandemic, and experienced more negative affect during the pandemic (Kroencke et al., 2020).

The differential reactivity model of personality and stress proposes that individual differences in personality influence people's reactivity to stressful events through associated differences in their choice of coping strategies, differences in the effectiveness of those chosen strategies, or both (Bolger \& Zuckerman, 1995). Thus, based on this model, we propose that more extraverted people react with greater perceived stressfulness to the COVID-19 pandemic because they are not able to fully rely on their preferred coping strategies for dealing with stress (e.g., socializing with other people, seeking social support) and, due to social distancing and quarantine measures, the use of these strategies may be less effective (e.g., relying on video calls instead of in-person meetings). More emotionally stable people, in contrast, should react with less perceived stressfulness to the pandemic because they can rely on coping strategies that do not involve other people, such as self-sufficient problem-focused or emotion-focused coping strategies (Carver, 1997; Zacher \& Rudolph, 2021). Consistent with these assumptions, a crosssectional survey study found that higher extraversion and lower emotional stability were related to higher perceived stress during the pandemic (Liu et al., 2020). Moreover, this study found that higher perceived threat and lower feelings of efficacy mediated the relationship between emotional stability and perceived stress. Interestingly, perceived threat did not mediate the relationship between extraversion and perceived stress, suggesting that "...the source of stress 
may stem from elsewhere (e.g., inability to socialize)...” (Liu et al., 2020, p. 1).

Hypothesis 2: The average level of perceived stressfulness of the COVID-19 pandemic is predicted by (a) extraversion, such that higher extraversion is associated with higher average levels of perceived stressfulness and (b) emotional stability, such that higher emotional stability is associated with lower average levels of perceived stressfulness.

We also draw from the differential reactivity model of personality and stress (Bolger \& Zuckerman, 1995) to explain potential effects of extraversion and emotional stability on the proposed changes in perceived stressfulness of the COVID-19 pandemic between early April 2020 and early September 2020. First, we argue that people with higher extraversion reacted more strongly and negatively to social restrictions during the early stages of the COVID-19 pandemic, which included the national "lockdown" and the slow "easing" of restrictions during the following few months (i.e., between early April 2020 and early July 2020). Thus, we expect that more extraverted people experienced increases in perceived stressfulness during this period compared to those with lower extraversion, who likely experienced declines in perceived stressfulness. However, we also expect that more extraverted people, as compared to their less extraverted counterparts, experienced stronger declines in perceived stressfulness in subsequent stages of the pandemic, during which social restrictions were almost completely reversed (i.e., the summer vacation period between early July 2020 and early September 2020).

Second, based on the differential reactivity model (Bolger \& Zuckerman, 1995), we further hypothesize that people with higher (vs. lower) emotional stability report stronger declines in perceived stressfulness during the early stages of the pandemic than during subsequent stages of the pandemic. More emotionally stable people should possess more relevant and effective coping strategies to deal with stressors associated with the pandemic (i.e., self- 
sufficient problem-focused and emotion-focused coping) that should particularly benefit the development of their emotional wellbeing (i.e., steeper reductions in perceived stressfulness) during and immediately after the national "lockdown," which represents the most demanding period of the pandemic. In contrast, the declines in perceived stressfulness should be weaker in subsequent stages of the pandemic, because the superior coping strategies of more emotionally stable people should have been less relevant or effective during this less demanding time.

Hypothesis 3: Changes in perceived stressfulness of the COVID-19 pandemic are predicted by (a) extraversion, such that those with higher extraversion experienced increases in perceived stressfulness during the early stages of the pandemic (i.e., between early April 2020 and early July 2020) and stronger declines in subsequent stages of the pandemic (i.e., between early July 2020 and early September 2020), and (b) emotional stability, such that those with higher emotional stability experienced stronger declines in perceived stressfulness during the early stages of the pandemic (i.e., between early April 2020 and early July 2020) than during subsequent stages of the pandemic (i.e., between early July 2020 and early September 2020).

\section{Method}

\section{Open Data and Materials}

Data for this study were collected as part of a larger longitudinal study on work experiences and behaviors of full-time employees in Germany. So far, one other study on a different topic, which is based upon different substantive variables, has been published from these data (Zacher \& Rudolph, 2021). Data and code to reproduce the analyses presented here, along with full results of all focal and supporting analyses, can be accessed via our online appendix (https://osf.io/yedwq/?view_only=8c9cdab1dbe74916bbd8afa611d159c7).

\section{Participants and Procedures}


We commissioned a professional and certified panel company to recruit participants from a nationally representative online panel in Germany. To be eligible to participate, employees had to be at least 18 years old and be working full-time. The panel company reimbursed employees for their participation with credit points that can later be exchanged for gift vouchers. For the baseline survey conducted in December of 2019 (Time [T] 0), 4,839 persons in the company's database were contacted and 2,439 persons initiated the survey and provided at least partial responses (e.g., demographics, personality; response rate of 50.40\%).

Data were collected at six time points, across ten months. Big Five personality traits were collected as part of the baseline survey in early December 2019 (T0). Perceived stressfulness was collected five times in the first week of April (T1), May (T2), July (T3), August (T4), and September (T5) of 2020. A summary of participant demographics can be found in Table 1. Of the $n=588$ participants who provided responses at all six measurement waves (T0-T5; effective T5 response rate $=24.10 \%), 371(63.1 \%)$ were male and $215(36.6 \%)$ were female $(2$ participants [0.3\%] did not indicate their sex). Their ages ranged from 21 to 69 years, with a mean age of 45.0 years $(S D=10.7)$.

Across the six waves of this study, some degree of attrition was observed. To understand the nature of attrition, we compared incomplete responders $(n=1,851)$ with panel responders on a number of demographic and substantive variables measured at T0 and T1 (see Table 1). In a logistic regression model, these predictors only accounted for about $3 \%$ of the variability in observed attrition $\left(R^{2}\right.$ Cox \& Snell $\left.=.028\right)$. As such, we are confident that systematic attrition is not of principle concern here. Complete details of this analysis are available in our online appendix. 
Table 1. Summary of Participant Demographics.

\begin{tabular}{|c|c|c|c|}
\hline & $\begin{array}{c}\text { Incomplete } \\
(\mathrm{N}=1851)\end{array}$ & $\begin{array}{c}\text { Complete } \\
(\mathrm{N}=588)\end{array}$ & p-value \\
\hline \multicolumn{4}{|l|}{ Sex } \\
\hline Male & $604(32.6 \%)$ & $371(63.1 \%)$ & $<.001$ \\
\hline Female & $700(37.8 \%)$ & $215(36.6 \%)$ & \\
\hline Missing & $547(29.6 \%)$ & $2(0.3 \%)$ & \\
\hline \multicolumn{4}{|l|}{ Age (Years) } \\
\hline Mean (SD) & $43.8(12.1)$ & $45.0(10.7)$ & .0197 \\
\hline Median [Min, Max] & $44.0[18.0,99.0]$ & $46.0[21.0,69.0]$ & \\
\hline Missing & $540(29.2 \%)$ & $0(0 \%)$ & \\
\hline \multicolumn{4}{|l|}{ Education } \\
\hline Lower Secondary School & $112(6.1 \%)$ & $31(5.3 \%)$ & .0443 \\
\hline Intermediate Secondary School & $474(25.6 \%)$ & $205(34.9 \%)$ & \\
\hline Upper Secondary School & $226(12.2 \%)$ & $105(17.9 \%)$ & \\
\hline College/University or Technical College & $484(26.1 \%)$ & $243(41.3 \%)$ & \\
\hline Missing & $555(30.0 \%)$ & $4(0.7 \%)$ & \\
\hline \multicolumn{4}{|l|}{ Monthly Household Income (Euros/Month) } \\
\hline 0-999 & $126(6.8 \%)$ & $20(3.4 \%)$ & $<.001$ \\
\hline $1000-1999$ & $231(12.5 \%)$ & $87(14.8 \%)$ & \\
\hline 2000-2999 & $288(15.6 \%)$ & $139(23.6 \%)$ & \\
\hline 3000-3999 & $275(14.9 \%)$ & $123(20.9 \%)$ & \\
\hline $4000-4999$ & $203(11.0 \%)$ & $119(20.2 \%)$ & \\
\hline $5000-5999$ & $96(5.2 \%)$ & $57(9.7 \%)$ & \\
\hline $6000-6999$ & $92(5.0 \%)$ & $43(7.3 \%)$ & \\
\hline Missing & $540(29.2 \%)$ & $0(0 \%)$ & \\
\hline \multicolumn{4}{|l|}{ T0 Extraversion } \\
\hline Mean (SD) & $4.33(1.26)$ & $4.23(1.32)$ & .147 \\
\hline Median [Min, Max] & $4.25[1.00,7.00]$ & $4.00[1.00,7.00]$ & \\
\hline Missing & $928(50.1 \%)$ & $0(0 \%)$ & \\
\hline \multicolumn{4}{|l|}{ T0 Agreeableness } \\
\hline Mean (SD) & $4.26(1.05)$ & $4.33(1.07)$ & .229 \\
\hline Median [Min, Max] & $4.25[1.25,7.00]$ & $4.25[1.00,7.00]$ & \\
\hline Missing & $928(50.1 \%)$ & $0(0 \%)$ & \\
\hline \multicolumn{4}{|l|}{ T0 Conscientiousness } \\
\hline Mean $(\mathrm{SD})$ & $5.12(0.999)$ & $5.22(0.997)$ & .0566 \\
\hline Median [Min, Max] & $5.00[1.50,7.00]$ & $5.25[2.50,7.00]$ & \\
\hline Missing & $928(50.1 \%)$ & $0(0 \%)$ & \\
\hline \multicolumn{4}{|l|}{ T0 Emotional Stability } \\
\hline Mean (SD) & $4.61(1.26)$ & $4.74(1.33)$ & .075 \\
\hline Median [Min, Max] & $4.75[1.00,7.00]$ & $4.75[1.00,7.00]$ & \\
\hline Missing & $928(50.1 \%)$ & $0(0 \%)$ & \\
\hline \multicolumn{4}{|l|}{ T0 Openness to Experience } \\
\hline Mean (SD) & $4.66(1.07)$ & $4.70(1.06)$ & .474 \\
\hline Median [Min, Max] & $4.60[1.20,7.00]$ & $4.60[1.20,7.00]$ & \\
\hline Missing & $928(50.1 \%)$ & $0(0 \%)$ & \\
\hline \multicolumn{4}{|l|}{ T1 Perceived Stressfulness } \\
\hline Mean (SD) & $2.82(1.01)$ & $2.92(1.00)$ & .127 \\
\hline Median [Min, Max] & $2.75[1.00,5.00]$ & $3.00[1.00,5.00]$ & \\
\hline Missing & $1439(77.7 \%)$ & $0(0 \%)$ & \\
\hline
\end{tabular}




\section{Measures}

Big Five Personality Traits. At T0, the Big Five personality traits were assessed with the 21-item German short version of the Big Five Inventory (John et al., 1991; Rammstedt \& John, 2005). Participants provided their responses on a 7-point scale ranging from 1 (strongly disagree) to 7 (strongly agree). Scale reliabilities were adequate and can be found in Table 2 .

Perceived Stressfulness of the COVID-19 Pandemic. At T1 through T5, four items from the German version of the stress appraisal measure (Delahaye et al., 2015; Peacock \& Wong, 1990) were used to assess perceived stressfulness of the COVID-19 pandemic. The instructions read, "The following questions refer to your thoughts about the COVID-19 pandemic. Please indicate how you appraise this situation." Two example items are "Does this situation create tension in you?" and "To what extent do you perceive this situation as stressful?" Responses were provided on a 5-point scale ranging from $1=$ not at all to $5=$ a great amount . This measure demonstrated good reliability $\left(\alpha_{\text {mean }}=.913\right)$ across all five time points; see also Table 2.

\section{Statistical Analyses}

We first considered measurement invariance models of perceived stressfulness; in summary of these models, metric invariance (i.e., equivalent factor loadings) was upheld (see online appendix for complete details of measurement invariance tests and additional supporting measurement models). The focal model depicted in Figure 1 was tested using latent growth curve modeling (LGCM), and extensions thereof, in a structural equation modeling (SEM) framework. All analyses were conducted in R using `lavaan` (Rosseel, 2012) with a maximum likelihood estimator. 
Table 2. Descriptive Statistics and Correlations.

\begin{tabular}{|c|c|c|c|c|c|c|c|c|c|c|c|c|c|c|c|c|}
\hline Variable & $\mathbf{M}$ & SD & 1. & 2. & 3. & 4. & 5. & 6. & 7. & 8. & 9. & 10. & 11. & 12. & 13. & 14. \\
\hline 1. T0 Sex & 1.37 & 0.48 & - & & & & & & & & & & & & & \\
\hline 2. T0 Age & 45.04 & 10.68 & -.076 & - & & & & & & & & & & & & \\
\hline 3. T0 Education & 3.96 & 0.99 & .028 & -.135 & - & & & & & & & & & & & \\
\hline 4. T0 Household Income & 3.98 & 1.54 & -.106 & .031 & .263 & - & & & & & & & & & & \\
\hline 5. T0 Extraversion & 4.23 & 1.32 & .058 & .148 & .003 & .126 & $(.835)$ & & & & & & & & & \\
\hline 6. T0 Agreeableness & 4.33 & 1.07 & .013 & .151 & -.093 & -.060 & .248 & $(.690)$ & & & & & & & & \\
\hline 7. T0 Conscientiousness & 5.22 & 1.00 & .136 & .231 & -.016 & .059 & .346 & .239 & $(.751)$ & & & & & & & \\
\hline 8. T0 Emotional Stability & 4.74 & 1.33 & -.128 & .204 & -.012 & .141 & .399 & .443 & .417 & $(.848)$ & & & & & & \\
\hline 9. T0 Openness to Experience & 4.70 & 1.06 & .149 & .166 & .088 & -.014 & .334 & .142 & .375 & .150 & $(.736)$ & & & & & \\
\hline 10. T1 Perceived Stressfulness & 2.92 & 1.00 & .103 & -.040 & -.003 & -.048 & -.062 & -.139 & -.038 & -.330 & .084 & $(.894)$ & & & & \\
\hline 11. T2 Perceived Stressfulness & 2.68 & 0.99 & .091 & -.042 & .069 & -.022 & -.101 & -.131 & -.132 & -.343 & .065 & .580 & $(.908)$ & & & \\
\hline 12. T3 Perceived Stressfulness & 2.49 & 1.01 & .048 & -.069 & .027 & -.058 & -.014 & -.129 & -.080 & -.341 & .044 & .533 & .605 & $(.921)$ & & \\
\hline 13. T4 Perceived Stressfulness & 2.49 & 0.98 & .043 & -.060 & .039 & -.005 & -.067 & -.158 & -.083 & -.364 & .010 & .527 & .604 & .715( & $(.915)$ & \\
\hline 14. T5 Perceived Stressfulness & 2.44 & 1.01 & .070 & -.124 & .039 & -.040 & -.101 & -.179 & -.093 & -.341 & .048 & .562 & .603 & .681 & .688 & $(.926)$ \\
\hline
\end{tabular}

Note. $N=588$. Reliability estimates $(\alpha)$, where available, are shown in parentheses along the diagonal.

$r_{x y} \leq|-.083| p<.05$ 
Figure 1. Conceptual Representation of Conditional Discontinuous Latent Growth Curve Model

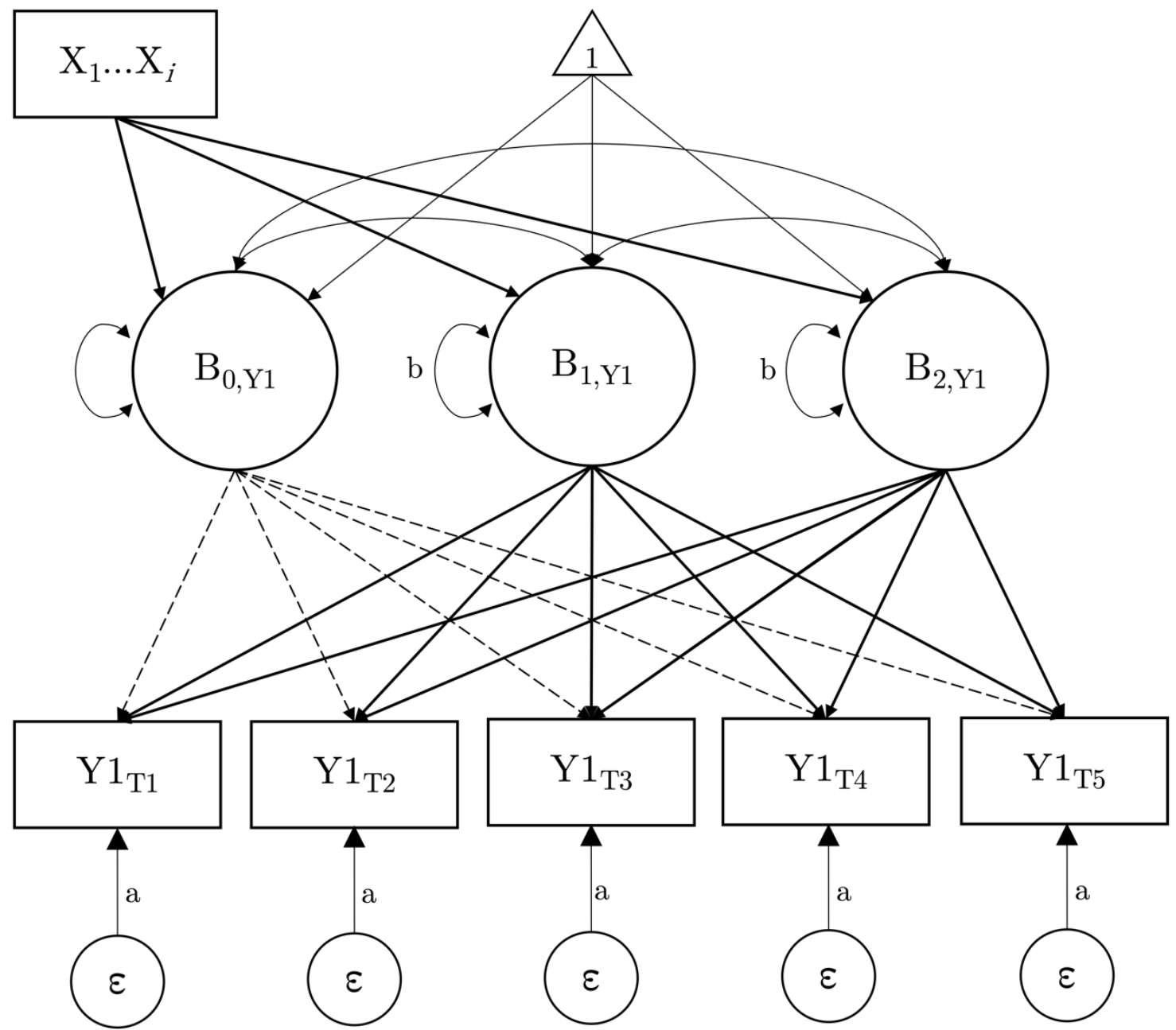

Note. $\mathrm{Y}_{\mathrm{T} 1-\mathrm{T} 5}$ indicates perceived stressfulness from $\mathrm{T} 1$ to $\mathrm{T} 5 . \mathrm{B}_{0, \mathrm{Y} 1}=$ Intercept; $\mathrm{B}_{1, \mathrm{Y} 1}=$ Slope 1 [early April 2020 to early July 2020; parameterized as: -3, -2, 0, 0, 0]; B2,Y1 = Slope 2 [early July 2020 to early September 2020; parameterized as: 0, 0, 0, 1, 2]. Common letters (i.e., "a," "b”) denote parameters fixed to equality. Dashed lines indicate parameters fixed to $1.0 . \mathrm{X}_{1} \ldots \mathrm{X}_{i}$ represents exogenous predictors of intercept and slope terms.

\section{Results}

Descriptive statistics and intercorrelations can be found in Table 2. To test our 
hypotheses, we first specified an unconditional LGCM to test for changes in perceived stressfulness between early April 2020 and early September 2020. We then specified an unconditional discontinuous LGCM, with two slopes specified to capture changes in perceived stressfulness between (a) early April 2020 and early July 2020 and (b) between early July 2020 and early September 2020. Finally, we specified a conditional discontinuous LGCM by regressing the intercept and two slopes of the discontinuous LGCM onto the Big Five personality traits as exogenous predictors.

First, the unconditional LGCM fit the data well $\left[\chi_{(14)}^{2}=81.97, p<.001, \mathrm{CFI}=.956\right.$, RMSEA $=.091$, SRMR $=.047]$. The slope of perceived stressfulness in this model was significant and negative $(B=-.090, S E=.007, p<.001)$. Second, the unconditional discontinuous LGCM also fit the data well $\left[\chi^{2}{ }_{(11)}=43.696, p<.001, \mathrm{CFI}=.979, \mathrm{RMSEA}=\right.$ $.071, \mathrm{SRMR}=.032]$. The first slope of perceived stressfulness, representing changes from early April 2020 to early July 2020 was significant and negative $(B=-.131, S E=.012, p<.001)$, whereas the second slope was not significant $(B=-.016, S E=.018, p<.381)$. Taken together, these two models suggest that, on average, (a) perceived stressfulness declined between early April 2020 and early September 2020, and (b) that the most appreciable declines in perceived stressfulness during this period occurred between early April 2020 and early July 2020. Thus, considering the first two models together, we find support for Hypothesis 1.

Third, the conditional discontinuous LGCM fit the data well $\left[\chi^{2}{ }_{(21)}=59.559, p<.001\right.$, $\mathrm{CFI}=.977, \mathrm{RMSEA}=.056, \mathrm{SRMR}=.021]$. In terms of predictors of the intercept, we observed that extraversion was positively $(B=.086, S E=.033, p=.008)$, whereas emotional stability was negatively $(B=-.312, S E=.035, p<.001)$ associated with average levels of perceived stressfulness. No other Big Five traits significantly predicted the intercept. In terms of variance 
explained, $R^{2}=.196(19.60 \%)$ of the variance in average levels of stressfulness was explained by the Big Five as a set. Thus, Hypothesis 2 was supported.

In terms of predictors of the slopes, we observed that extraversion was associated with increases in perceived stressfulness from early April 2020 to early July $2020(B=.027, S E=$ $.011, p=.015)$ and decreases in perceived stressfulness from early July 2020 to early September $2020(B=-.038, S E=.016, p=.014)$. No other Big Five traits were predictors of either slope. In terms of variance explained, $R^{2}=.044(4.40 \%)$ of the variance in changes in stressfulness between early April 2020 and early July 2020 was explained by the Big Five as a set, whereas $R^{2}$ $=.092(9.20 \%)$ of the variance in changes in stressfulness between early July 2020 and early September 2020 was explained by the Big Five as a set. Thus, Hypothesis 3 was partially supported. Complete results of these models and their parameter estimates are available in our online appendix.

\section{Discussion}

Overall, our hypotheses received either complete or at least partial support. Supporting Hypothesis 1, our unconditional LGCM suggests that, on average, there was a decline in the perceived stressfulness of the COVID-19 pandemic between early April 2020 and early September 2020. Moreover, our unconditional discontinuous LGCM suggests that there was an on-average steeper decline during the early stages of the pandemic (i.e., between early April 2020 and early July 2020) than during subsequent stages of the pandemic (i.e., the summer vacation period between early July 2020 and early September 2020). These findings are consistent with our expectations based on event and transition theories, which suggest that individuals' adaptation to strong and stressful events follows an L-shaped pattern over time (Bliese et al., 2017; Morgeson et al., 2015; Schlossberg, 1981). The results extend earlier 
research on perceived stress, mental health, and subjective wellbeing during the COVID-19 pandemic, which has mostly used cross-sectional study designs (e.g., Modersitzki et al., 2020) or focused on shorter timeframes (e.g., March 2020 to May 2020; Zacher \& Rudolph, 2021).

Additionally, supporting Hypothesis 2, our unconditional discontinuous LGCM suggests that the average level of perceived stressfulness of the COVID-19 pandemic was predicted by extraversion (i.e., higher extraversion is associated with higher average levels of perceived stressfulness) and emotional stability (i.e., higher emotional stability is associated with lower average levels of perceived stressfulness). It is important to point out that these effects were observed when controlling for other Big Five traits (i.e., conscientiousness, agreeableness, openness). Overall, these results are consistent with the differential reactivity model of personality and stress (Bolger \& Zuckerman, 1995) and recent findings in the context of the COVID-19 pandemic, suggesting that both extraversion (Nikčević et al., 2020; Wijngaards et al., 2020) and emotional stability (Kocjan et al., 2020; Kroencke et al., 2020; Lee \& Crunk, 2020; Liu et al., 2020; Pradhan et al., 2020) relate to general levels of perceived stress, mental health, and subjective wellbeing during the COVID-19 pandemic.

Finally, partially supporting Hypothesis 3 based on the differential reactivity model, our conditional discontinuous LGCM suggests that changes in perceived stressfulness of the COVID-19 pandemic were predicted by extraversion. Specifically, we found support for the prediction that those with higher extraversion experienced an increase in perceived stressfulness during the early stages of the pandemic (i.e., between early April 2020 and early July 2020), followed by a stronger decline in subsequent stages of the pandemic (i.e., the summer vacation period between early July 2020 and early September 2020). In contrast, our predictions regarding emotional stability predicting changes in perceived stressfulness of the COVID-19 pandemic 
were not upheld, hence partial support is garnered for this hypothesis. As with predictions regarding average levels, the significant effects of extraversion on changes in perceived stressfulness were observed when controlling for the other Big Five traits.

\section{Implications for Theory, Research, and Practice}

Taken as a whole, our results suggest that, although there were overall declines in perceived stressfulness of the COVID-19 pandemic from early April 2020 to early September 2020, these changes were not uniform (i.e., they were discontinuous in nature) and they were conditional upon individual differences in extraversion. Thus, our findings support core predictions of event and transition theories (Bliese et al., 2017; Morgeson et al., 2015), suggesting that people react and adapt to stressful events. They also support predictors of the differential reactivity model (Bolger \& Zuckerman, 1995), suggesting that people's personality impacts, to some extent, these reactions and adaptations to stressful situations - on average, and in terms of changes in perceived stressfulness over time. These findings are consistent with a meta-synthesis of 22 meta-analyses on personality and mental health (with the number of primary studies $[k]$ ranging from 453 to 734 ), which showed that neuroticism (i.e., the reverse of emotional stability; $\rho=-.27)$ and extraversion $(\rho=.11)$ had small to moderate relationships with mental health (Strickhouser et al., 2017). Interestingly, and in contrast to the findings of the current study, the meta-synthesis also reported significant associations of conscientiousness $(\rho=$ $.22)$, agreeableness $(\rho=.21)$, and openness to experience $(\rho=.06)$ with mental health.

Our results also point to the importance of considering not only linear or "continuous" change, but also discontinuous change, in important psychological responses (e.g., stress appraisals) during transition processes, and should inform future longitudinal research on individual adaptation and resilience (i.e., positive adaptation in a context characterized by 
adversity; Masten, 2001) conducted during crisis situations (Bliese et al., 2017). Our findings regarding extraversion as a predictor of changes in perceived stressfulness over time are only partially consistent with a recent meta-analysis on personality and resilience (i.e., measured as a trait and not as a process), which found moderate and positive relationships for all Big Five traits (e.g., $\rho=.42$ for extraversion, $\rho=-.46$ for neuroticism; Oshio et al., 2018). Finally, our results may suggest that it took more extraverted people longer to adapt, with respect to their perceptions of stressfulness, to the changes imposed by the COVID-19 pandemic. As such, our findings imply that interventions that are designed to help people manage the stressfulness of crisis situations, especially those that limit social contacts, could be targeted especially toward those with higher extraversion.

\section{Limitations and Directions for Future Research}

Our longitudinal research design has a number of strengths; for example, temporally separating the measurement of Big Five traits, collected in early December 2019, from the collection of perceived stressfulness should alleviate concerns about common method bias. However, there are certain limitations of this study that bear consideration, especially in the design of future research. For example, owing to our design, we could not control for "baseline" levels of perceived stressfulness (e.g., people's average levels of day-to-day perceived stress). However, given that our measurement of perceived stressfulness pertains specifically to appraisals of stressors associated with the COVID-19 pandemic, this is perhaps not of great concern. Still, ideally, we would have been able to capture participants' perceptions of the pandemic before early April 2020 (e.g., in early March 2020, when the first cases and deaths were reported in Germany), and we encourage future research conducted during crisis situations to consider the timing of such baseline measurements. That said, we contend that, given the 
timeline for lockdown restrictions, our timeframe is still meaningful in this regard. Another potential limitation of our longitudinal study design may be that we cannot rule out effects associated with prior survey experiences on perceived stressfulness of the COVID-19 pandemic. Such retest effect could be minimized in future research through the use of different forms of the same questionnaire in successive measurement waves (Salthouse \& Tucker-Drob, 2008).

We also did not consider any conditional mechanisms that might moderate the relationships between Big Five personality traits and average levels and changes in perceived stressfulness (e.g., contextual variables such as differences in employment status, caregiving responsibilities). Future studies are encouraged to also collect measures of coping (e.g., especially social forms, such as seeking instrumental and emotional support) and behavioral measures of social distancing to better understand the links between extraversion and average levels and changes in perceived stressfulness. In addition to social needs and coping behaviors, future research could explore the neurological underpinnings of extraversion and emotional stability (e.g., arousal, inhibition; see Matthews \& Gilliland, 1999) and how they might relate to perceived stressfulness of the COVID-19 pandemic. Moreover, future research could examine interactive effects of different personality traits, and of personality traits and other individual difference characteristics, in predicting responses to the COVID-19 pandemic. For instance, a recent cross-sectional study with 466 participants in Switzerland found that emotion suppression was related to lower affective wellbeing among people with higher, but not lower extraversion (Gubler et al., 2020). Finally, future longitudinal studies on perceived stressfulness of the COVID-19 pandemic could focus on additional individual difference characteristics as predictors. For instance, recent cross-sectional studies have examined personality dimensions based on reinforcement sensitivity theory (e.g., reward reactivity; Bacon \& Corr, 2020), as well 
as "dark personality traits" (e.g., narcissism, sadism; Hardin et al., 2020) in this context.

\section{Conclusions}

The first goal of this study, based on event and transition theories, was to examine changes in perceived stressfulness of the COVID-19 pandemic in Germany between early April 2020 and early September 2020. The second goal was to test predictions based upon the differential reactivity model of personality and stress that consider Big Five personality traits as predictors of individual differences and changes in perceived stressfulness across this timespan. Our results showed that, on average, perceived stressfulness declined between early April 2020 and early September 2020, and that this effect was stronger between early April 2020 and early July 2020. We also found that emotional stability was associated with lower, whereas extraversion was associated with higher, average levels of perceived stressfulness. Finally, our results suggest that extraversion was associated with increases in perceived stressfulness between early April 2020 and early July 2020 and decreases in perceived stressfulness between early July 2020 and early September 2020. Our hope is that these results are informative of the role that personality plays during crises, especially with respect to the ways in which people appraise the stressfulness of such situations. 


\section{References}

Bacon, A. M., \& Corr, P. J. (2020). Coronavirus (COVID-19) in the United Kingdom: A personality-based perspective on concerns and intention to self-isolate. British Journal of Health Psychology. https://doi.org/10.1111/bjhp.12423

Bliese, P. D., Adler, A. B., \& Flynn, P. J. (2017). Transition processes: A review and synthesis integrating methods and theory. Annual Review of Organizational Psychology and Organizational Behavior, 4, 263-286. https://doi.org/10.1146/annurev-orgpsych-032516113213

Bolger, N., \& Schilling, E. A. (2006). Personality and the problems of everyday life: The role of neuroticism in exposure and reactivity to daily stressors. Journal of Personality, 59(3), 355-386. https://doi.org/10.1111/j.1467-6494.1991.tb00253.x

Bolger, N., \& Zuckerman, A. (1995). A framework for studying personality in the stress process. Journal of Personality and Social Psychology, 69(5), 890-902. https://doi.org/10.1037/0022-3514.69.5.890

Carver, C. S. (1997). You want to measure coping but your protocol' too long: Consider the brief cope. International Journal of Behavioral Medicine, 4(1), 92-100. https://doi.org/10.1207/s15327558ijbm0401_6

Costa, P. T., \& McCrae, R. R. (1980). Influence of extraversion and neuroticism on subjective well-being: Happy and unhappy people. Journal of Personality and Social Psychology, 38(4), 668-678. https://doi.org/10.1037/0022-3514.38.4.668

Delahaye, M., Stieglitz, R. D., Graf, M., Keppler, C., Maes, J., \& Pflueger, M. (2015). Deutsche Übersetzung und Validierung des Stress Appraisal Measure (SAM) [German translation and validation of the Stress Appraisal Measure (SAM)]. Fortschritte der Neurologie • 
Psychiatrie, 83(05), 276-285. https://doi.org/10.1055/s-0034-1399727

Digman, J. M. (1990). Personality structure: Emergence of the five-factor model. Annual Review of Psychology, 41, 417-440. https://doi.org/10.1146/annurev.ps.41.020190.002221

Folk, D., Okabe-Miyamoto, K., Dunn, E., \& Lyubomirsky, S. (2020). Did social connection decline during the first wave of COVID-19? The role of extraversion. Collabra: Psychology, 6(1), 37. https://doi.org/10.1525/collabra.365

Gubler, D. A., Makowski, L. M., Troche, S. J., \& Schlegel, K. (2020). Loneliness and wellBeing during the Covid-19 pandemic: Associations with personality and emotion regulation. Journal of Happiness Studies. https://doi.org/10.1007/s10902-020-00326-5

Hardin, B. S., Smith, C. V., \& Jordan, L. N. (2020). Is the COVID-19 pandemic even darker for some? Examining dark personality and affective, cognitive, and behavioral responses to the COVID-19 pandemic. Personality and Individual Differences, 110504. https://doi.org/10.1016/j.paid.2020.110504

Hayes, N., \& Joseph, S. (2003). Big 5 correlates of three measures of subjective well-being. Personality and Individual Differences, 34(4), 723-727. https://doi.org/10.1016/S01918869(02)00057-0

Hobfoll, S. E. (2011). Conservation of resources theory: Its implications for stress, health, and resilience. In S. Folkman (Ed.), The Oxford handbook of stress, health, and coping (pp. 127-147). Oxford University Press.

Hotard, S. R., McFatter, R. M., McWhirter, R. M., \& Stegall, M. E. (1989). Interactive effects of extraversion, neuroticism, and social relationships on subjective well-being. Journal of Personality and Social Psychology, 57(2), 321-331. https://doi.org/10.1037/0022$\underline{3514.57 .2 .321}$ 
John, O. P., Donahue, E. M., \& Kentle, R. L. (1991). The Big Five Inventory (Version 4a and 54). University of California, Institute of Personality and Social Research.

Kocjan, G. Z., Kavčič, T., \& Avsec, A. (2020). Resilience matters: Explaining the association between personality and psychological functioning during the COVID-19 pandemic. International Journal of Clinical and Health Psychology. https://doi.org/10.1016/j.ijchp.2020.08.002

Kroencke, L., Geukes, K., Utesch, T., Kuper, N., \& Back, M. (2020). Neuroticism and emotional risk during the COVID-19 pandemic. Journal of Research in Personality. https://doi.org/10.1016/j.jrp.2020.104038

Lazarus, R. S., \& Folkman, S. (1984). Stress, appraisal, and coping. Springer.

Lee, S. A., \& Crunk, E. A. (2020). Fear and psychopathology during the COVID-19 crisis: neuroticism, hypochondriasis, reassurance-seeking, and coronaphobia as fear factors. OMEGA - Journal of Death and Dying. https://doi.org/10.1177/0030222820949350

Liu, S., Lithopoulos, A., Zhang, C. Q., Garcia-Barrera, M. A., \& Rhodes, R. E. (2020). Personality and perceived stress during COVID-19 pandemic: Testing the mediating role of perceived threat and efficacy. Personality and Individual Differences, 168, 110351. https://doi.org/10.1016/j.paid.2020.110351

Masten, A. S. (2001). Ordinary magic: Resilience processes in development. American Psychologist, 56, 227-239. https://doi.org/10.1037//0003-066X.56.3.227

Matthews, G., \& Gilliland, K. (1999). The personality theories of H.J. Eysenck and J.A. Gray: A comparative review. Personality and Individual Differences, 26(4), 583-626. https://doi.org/10.1016/S0191-8869(98)00158-5

Modersitzki, N., Phan, L. V., Kuper, N., \& Rauthmann, J. F. (2020). Who is impacted? 
Personality predicts individual differences in psychological consequences of the COVID19 pandemic in Germany. Social Psychological and Personality Science. https://doi.org/10.1177/1948550620952576

Morgeson, F. P., Mitchell, T. R., \& Liu, D. (2015). Event system theory: An event-oriented approach to the organizational sciences. Academy of Management Review, 40(4), 515537. https://doi.org/10.5465/amr.2012.0099

Nikčević, A. V., Marino, C., Kolubinski, D. C., Leach, D., \& Spada, M. M. (2020). Modelling the contribution of the Big Five personality traits, health anxiety, and COVID-19 psychological distress to generalised anxiety and depressive symptoms during the COVID-19 pandemic. Journal of Affective Disorders, 279, 578-584.

\section{https://doi.org/10.1016/j.jad.2020.10.053}

Oshio, A., Taku, K., Hirano, M., \& Saeed, G. (2018). Resilience and Big Five personality traits: A meta-analysis. Personality and Individual Differences, 127, 54-60. https://doi.org/10.1016/j.paid.2018.01.048

Peacock, E. J., \& Wong, P. T. (1990). The stress appraisal measure (SAM): A multidimensional approach to cognitive appraisal. Stress Medicine, 6(3), 227-236. https://doi.org/10.1002/smi.2460060308

Pradhan, M., Chettri, A., \& Maheshwari, S. (2020). Fear of death in the shadow of COVID-19: The mediating role of perceived stress in the relationship between neuroticism and death anxiety. Death Studies. https://doi.org/10.1080/07481187.2020.1833384

Prime, H., Wade, M., \& Browne, D. T. (2020). Risk and resilience in family well-being during the COVID-19 pandemic. American Psychologist. https://doi.org/10.1037/amp0000660

Rammstedt, B., \& John, O. P. (2005). Kurzversion des Big Five Inventory (BFI-K) [Short 
version of the Big Five Inventory (BFI-K): Development and validation of an economic inventory for assessment of the five factors of personality]. Diagnostica, 51(4), 195-206. https://doi.org/10.1026/0012-1924.51.4.195

Rosseel, Y. (2012). lavaan: An R package for structural equation modeling. Journal of Statistical Software, 48(2), 1-36. https://doi.org/10.18637/jss.v048.i02

Rudolph, C. W., Allan, B., Clarke, M., Hertel, G., Hirschi, A., Kunze, F., Shockley, K., Shoss, M., Sonnentag, S., \& Zacher, H. (2020). Pandemics: Implications for research and practice in industrial and organizational psychology. Industrial and Organizational Psychology: Perspectives on Science and Practice. https://doi.org/https://psyarxiv.com/k8us2

Ryan, R. M., \& Deci, E. L. (2000). Self-determination theory and the facilitation of intrinsic motivation, social development, and well-being. American Psychologist, 55(1), 68-78. https://doi.org/10.1037/0003-066X.55.1.68

Salthouse, T. A., \& Tucker-Drob, E. M. (2008). Implications of short-term retest effects for the interpretation of longitudinal change. Neuropsychology, 22(6), 800-811. https://doi.org/10.1037/a0013091

Schlossberg, N. K. (1981). A model for analyzing human adaptation to transition. The Counseling Psychologist, 9(2), 2-18. https://doi.org/10.1177/001100008100900202

Sibley, C., Greaves, L., Satherley, N., Wilson, M. S., Overall, N., Lee, C., Milojev, P., Bulbulia, J., Osborne, D., Milfont, T., Houkamau, C. A., Duck, I. M., Vickers-Jones, R., \& Barlow, F. (2020). Effects of the COVID-19 pandemic and nationwide lockdown on trust, attitudes towards government, and wellbeing. American Psychologist, 75(5), 618-630. https://doi.org/10.1037/amp0000662 
Somma, A., Gialdi, G., Krueger, R. F., Markon, K. E., Frau, C., Lovallo, S., \& Fossati, A. (2020). Dysfunctional personality features, non-scientifically supported causal beliefs, and emotional problems during the first month of the COVID-19 pandemic in Italy. Personality and Individual Differences, 165, 110139. https://doi.org/10.1016/j.paid.2020.110139

Strickhouser, J. E., Zell, E., \& Krizan, Z. (2017). Does personality predict health and well-being? A metasynthesis. Health Psychology, 36(8), 797-810. https://doi.org/10.1037/hea0000475

Volk, A. A., Brazil, K. J., Franklin-Luther, P., Dane, A. V., \& Vaillancourt, T. (2020). The influence of demographics and personality on COVID-19 coping in young adults. Personality and Individual Differences, 168, 110398. https://doi.org/10.1016/j.paid.2020.110398

Vollrath, M. (2001). Personality and stress. Scandinavian Journal of Psychology, 42(4), 335-347. https://doi.org/10.1111/1467-9450.00245

Wijngaards, I., de Zilwa, S. C. S., \& Burger, M. J. (2020). Extraversion moderates the relationship between the stringency of COVID-19 protective measures and depressive symptoms. Frontiers in Psychology, 11, 568907. https://doi.org/10.3389/fpsyg.2020.568907

Zacher, H., \& Rudolph, C. W. (2021). Individual differences and changes in subjective wellbeing during the early stages of the COVID-19 pandemic. American Psychologist, 76, 50-62. https://doi.org/10.1037/amp0000702 